\title{
Rapid isolation of non-aflatoxigenic Aspergillus flavus strains
}

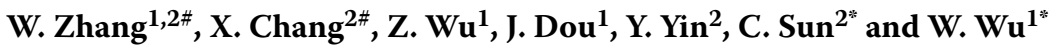 \\ ${ }^{1}$ Department of Biological and Agricultural Engineering, Jilin University, No. 5988 Renmin Street, Changchun 130022, \\ China P.R.; ${ }^{2}$ Academy of National Food and Strategic Reserves Administration P.R.C, No.11 Baiwanzhuang Avenue, Xicheng \\ District, Beijing 100037, China P.R.; scp@chinagrain.org; wuwf@jlu.edu.cn; " These authors contributed equally to the work \\ and should be regarded as co-first authors
}

Received: 23 June 2019 / Accepted: 20 January 2020

(c) 2020 Wageningen Academic Publishers

OPEN ACCESS CC) R() RESEARCH ARTICLE

\begin{abstract}
In the present study, a method for screening non-aflatoxigenic Aspergillus flavus in soil samples collected from major peanut-growing regions of China was developed. The single colonies were picked and cultured on Aspergillus flavus and parasiticus agar (AFPA). If the reverse side of the colony on AFPA was orange-coloured, it was considered $A$. flavus or Aspergillus parasiticus. After the genomic DNA of each strain was extracted, 28S rRNA and calmodulin were amplified and sequenced to determine the species. The key gene, aflR, was amplified and digested via polymerase chain reaction-restriction fragment length polymorphism. The aflatoxigenic A. flavus and the nonaflatoxigenic $A$. flavus and $A$. parasiticus were distinguished by enzyme digestion of aflR. 156 strains of $A$. flavus were screened, which consisted of 135 aflatoxigenic and 21 non-aflatoxigenic strains. The aflatoxin producing ability of each strain was confirmed using solid-state fermentation experiments. Using the method developed in the present study, we confirmed that the non-aflatoxigenic $A$. flavus strains isolated lost their capacity to produce aflatoxins. Considering there could be some alterations in other functional genes, some non-aflatoxigenic strains could be identified inaccurately as aflatoxigenic strains, although that did not occur in the present study. The growth of non-aflatoxigenic $A$. flavus was observed, and the most rapidly growing non-aflatoxigenic strain was selected for plate confrontation assays and toxic mixed culture experiments. The inhibition rate of non-aflatoxigenic $A$. flavus against aflatoxigenic $A$. flavus was 55.4 and $72.6 \%$ in potato dextrose agar (PDA) plate and natural soybean medium, respectively. The screened non-aflatoxigenic $A$. flavus strains provide a microbial resource for biological control of aflatoxin contamination.
\end{abstract}

Keywords: aflatoxins, aflR, PCR-RFLP, solid-state fermentation, inhibition

\section{Introduction}

Aflatoxins (AFs) are a group of secondary metabolites in Aspergillus fungi, such as Aspergillus flavus, Aspergillus parasiticus and Aspergillus nomius (Kowalska et al., 2017; Varga et al., 2009). AFs have been listed as the most dangerous mycotoxins in food due to their high carcinogenic and teratogenic toxicity. For instance, the carcinogenicity of $\mathrm{AFB}_{1}$ is 75 -fold of that of the standard carcinogen dimethyl nitrosamine (Horn and Dorner, 1998; IARC, 1993) and 10 - and 68-fold of that of potassium cyanide and arsenic, respectively. The intake of only $0.294 \mathrm{mg} / \mathrm{kg} \mathrm{AFB}_{1}$ would subject sensitive animals to acute poisoning and death $(\mathrm{Li}$ et al., 2009). In 1994, the International Agency for Research on Cancer (IARC) listed $\mathrm{AFB}_{1}$ as a Class I carcinogen (Horn and Dorner, 1999). Consequently, the European Union issued a unified food aflatoxin limit standard in its member states and set the limits of $\mathrm{AFB}_{1}$ and total $\mathrm{AF}$ (aflatoxin $\mathrm{B}_{1}$ $+B_{2}+G_{1}+G_{2}$ ) at 2 and $4 \mu \mathrm{g} / \mathrm{kg}$, respectively, in peanuts and other foods (EC, 2006).

AFs exhibit remarkable stability and hardly degrade under food-processing environments (Liu and $\mathrm{Wu}, 2010$ ). The occurrence and accumulation of AFs in peanut and other cereals have caused major economic losses globally. Consequently, strategies for reducing aflatoxin pollution in the course of crop development are urgently required. 
Introducing non-toxigenic $A$. flavus or $A$. parasiticus to microbial flora in soils opens a new horizon for controlling AF-producing microrganisms, which has been reported to be remarkably effective in reducing AF-contamination prior to harvest (Bandyopadhyay et al., 2016; Dorner and Lamb, 2006). As early as the 1990s, a study proposed the introduction of non-toxigenic strains of A. flavus in soil in order to reduce the aflatoxin concentrations in cotton seeds (Cotty, 1990). In addition, Dorner et al. (1992) pointed out that the spread of non-toxigenic $A$. parasiticus strains in peanut-growing soil could decrease the aflatoxin concentrations in peanuts by 83-85\% (Dorner et al., 1992). At present, commercialised non-toxigenic strains of $A$. flavus are registered in numerous countries. For example, the US Environmental Protection Association has registered two non-toxigenic strains of $A$. flavus to control cotton and peanut aflatoxin contamination, and both have been extensively tested in experimental fields in several states in the United States (Cardwell et al., 2008). In Africa, Aflasafe ${ }^{\text {тм }}$ has been produced using a mixture of four non-toxigenic strains (Bandyopadhyay et al., 2016). In Italy, the commercial biocontrol product, AF-X1, which originates from the nontoxigenic A.flavus strain MUCL54911, is currently used in maize (Mauro et al., 2018). In Australia and China, strains of non-toxigenic $A$. flavus that can effectively inhibit aflatoxin production have also been screened, and the strains have reduced the number of toxin-producing strains by more than 95\% (Pitt and Hocking, 2006; Yin et al., 2008). Introducing non-toxigenic $A$. flavus and $A$. parasiticus to control the microbial flora in the soil could lead to the replacement of the original toxin-producing strain in the soil in the course of crop growth, which is very effective in reducing aflatoxin contamination prior to harvesting (Dorner and Lamb, 2006). Dorner and Horn (2007) observed that A. flavus, as opposed to $A$. parasiticus, is more likely to colonise peanuts in soil (Dorner and Horn, 2007).

The key aspect of the strategy is the rapid screening and identification of competitive non-aflatoxigenic $A$. flavus strains. The identification of Aspergillus section Flavi strains has been based on polyphasic approaches, including chemical, morphological and molecular characterisation (Paula et al., 2009).

Barros et al. (2010) used AFLP to compare 82 isolates of Aspergillus section Flavi and clearly separated A. flavus and $A$. parasiticus using cluster analysis. The comparison of fingerprints also revealed several specific markers for each group of isolates; however, no genotypical differences in passage were observed between aflatoxigenic and nonaflatoxigenic producers (Barros et al., 2010).

Aflatoxin synthesis involves a complex 21-step enzymatic reaction process (Bhatnagar et al., 2003). Most of the genes involved in the synthesis are in specific gene clusters, which are transcribed and translated by genes of the gene clusters (Yu et al., 2000). Gene clusters are common secondary metabolisms in cells (Keller and Hohn, 1997). The presence of gene clusters is one of the key mechanism of regulation of the aflatoxin biosynthesis pathway and other secondary metabolic pathways (Georgianna and Payne, 2009). AflR, a key gene in the aflatoxin biosynthesis pathway, plays an important role in toxin production. In addition, as a key protein for aflatoxin synthesis and a major positive transcription factor, the AflR protein regulates the transcription of other genes in the aflatoxin biosynthesis pathway (Ehrlich et al., 1998, 2003; Georgianna and Payne, 2009; Rokas et al., 2007; Yu et al., 2002). Most aflatoxin synthesis related genes are regulated by the AflR protein (Bhatnagar et al., 2006; Galagan et al., 2005; Matsushima et al., 2001; Nierman et al., 2005; Price et al., 2010). Some mutation points in the $a f l R$ promoter region were revealed in none- $\mathrm{AFB}_{1}$-producing $A$. flavus strains via gene analysis using OMIGA (Oxford Molecular Ltd., Cambridge, UK), and one or some of the mutation sites could be associated with aflatoxin production (Chen and Liu, 2006).

The aim of the present study was to develop a novel and efficient method for rapid isolating non-aflatoxigenic strains of $A$. flavus and to offer a microbial resource for the biological control of aflatoxin contamination.

\section{Materials and methods}

\section{Fungal isolates and culture conditions}

Soil samples were collected from four major peanut-growing regions of China, including Tangshan City in Hebei Province, Zhengyang and Wuyang City in Henan Province, Xiangyang City in Hubei Province, in 2017 and 2018. Under sterilised conditions, $10 \mathrm{~g}$ of each sample was placed in a $250 \mathrm{ml}$ conical flask and $90 \mathrm{ml}$ of $0.1 \%$ sterile peptone water solution (w/v) added. The mixture was sealed and shaken for $30 \mathrm{~min}$. Subsequently, $1 \mathrm{ml}$ of the solution was mixed in a centrifugal tube containing $9 \mathrm{ml}$ of $0.1 \%$ peptone sterile water, forming a 1:100 dilution solution (Zanon et al., 2013). Based on the procedure, a gradient sample dilution solution was prepared using 10-fold diluted gradient dilution; $100 \mu \mathrm{l}$ of $10^{-2}$ and $10^{-3}$ gradient soil dilution solution was added to Dicloran $18 \%$ glycerol medium salt Czapek Dox (CZ) agar (DG18). The plate was placed upside down in an incubator and cultured at $30{ }^{\circ} \mathrm{C}$ for four days. Subsequently, a single colony was picked and transferred to a new DG18 plate. After three days of culture, the spores were transferred into $20 \%$ glycerol and stored at $-80^{\circ} \mathrm{C}$ for subsequent analyses.

Twelve Aspergillus strains, including two A. parasiticus strains, eight $A$. flavus strains, one Aspergillus oryzae strain and one Aspergillus sojae strain, were used as the internal references. Their identities, numbers and origins are listed in Supplementary Table S1. All isolates were maintained in $20 \%$ glycerol at $-80{ }^{\circ} \mathrm{C}$. 


\section{Phenotypic characterisation}

Each isolate was cultivated on Aspergillus flavus and parasiticus agar (AFPA) purchased from Qingdao Haibo Biotechnology Co., Ltd. (Qingdao, China P.R.; peptone $10 \mathrm{~g} / \mathrm{l}$; yeast soaking powder $20 \mathrm{~g} / \mathrm{l}$; ferric ammonium citrate $0.5 \mathrm{~g} / \mathrm{l}$; Dichloran $0.002 \mathrm{~g} / \mathrm{l}$; chloramphenicol 0.1g/l; agar $15 \mathrm{~g} / \mathrm{l} ; \mathrm{pH} 6.3 \pm 0.2$ ) and cultured at $30^{\circ} \mathrm{C}$ for $72 \mathrm{~h}$ in the dark. Both $A$. flavus and $A$. parasiticus produce aspergillic acid, which reacts with ferric citrate in AFPA medium to generate an orange pigment (Baquião et al., 2013). Each strain was inoculated on a petri dish containing Czapek agar and incubated at $30^{\circ} \mathrm{C}$ for 14 days. If no sclerotia were observed under the conditions, the strain was not considered sclerotia-producing. Ten sclerotia were randomly selected in each medium for the observation of diameter, shape and colour. Sclerotia with diameter $<400 \mu \mathrm{m}$ and $>400 \mu \mathrm{m}$ were classified as S-type and L-type, respectively (Cotty, 1989).

\section{DNA extraction and amplification}

DNA was extracted using the GV-filamentous fungi genomic DNA extraction kit (Beijing Dingguo Changsheng Biotechnology Co. Ltd., Beijing, China P.R.) according to the manufacturer's instructions. Two regions of the genome were named the $28 S r R N A$ and the partial calmodulin gene. The $28 S r R N A$ was amplified using the $N L_{1} / N L_{4}$ primer pair that was designed based on the sequences of aflatoxin biosynthesis genes in A. flavus (GenBank accession No. AY510451.1) (Jiang et al., 2009). The calmodulin gene was amplified using the $C L_{f} / C L_{2 A}$ primers (O'Donnell et al., 2000). The amplification products were sequenced by a biotech company (BGI, Shenzhen, China P.R.), and then the sequences were aligned using data from the US National Center for Biotechnology Information database, which classified the species preliminarily. The sequences of the primers are listed in Table 1.

\section{Table 1. Sequences of primers and probes used in the study.}

$\begin{array}{ll}\text { Name } & \text { Sequences } \\ \text { afIR }_{1} & \text { 5'-AGAATAGCTTCGCAGGGTGGT-3' } \\ \text { afl }_{2} & \text { 5'-AGTCTGGGAGGAACGGATCG-3' } \\ \text { Pafl }_{1} & \text { 5'-AACCGCATCCACAATCTCAT-3' } \\ \text { PaflR }_{2} & \text { 5'-AGTGCAGTTCGCTCAGAACA-3' } \\ \mathrm{NL}_{1} & \text { 5'-TGCGTTGATTACGTCCCTGC-3' } \\ \mathrm{NL}_{4} & \text { 5'-GGTCCGTGTTTCAAGACGG-3' } \\ \mathrm{CL}_{1} & \text { 5'-GARTWCAAGGAGGCCTTCTC-3' } \\ \mathrm{CL}_{2 \mathrm{~A}} & \text { 5'-TTTTTGCATCATGAGTTGGAC-3' }\end{array}$

\section{PCR-RFLP of the afIR gene}

The primer pairs were designed based on comparisons of aflR and its promoter involved in the aflatoxin biosynthesis among A. flavus, A. parasiticus, A. oryzae and A. sojae. The $a f l R$ and promoter gene were amplified using the $a f l R_{1} /$ $a f l R_{2}$ and $P a f l R_{1} / P a f l R_{2}$ primer pairs, respectively (Table 1). The PCR-RFLP results of the twelve Aspergillus fungi listed in Supplementary Table S1 are presented as examples.

PCR was conducted using a C1000 PCR instrument (BioRad, Hercules, CA, USA). The $25 \mu$ PCR system consisted of $12.5 \mu \mathrm{l}$ of Premix PrimeSTAR HS enzymes, $0.5 \mu \mathrm{l}$ of upstream primers, $0.5 \mu \mathrm{l}$ of downstream primers and $10.5 \mu \mathrm{l}$ of ultra-pure water. To obtain pure PCR products, we designed a special PCR process to apply the primer annealing temperature cumulatively. The reaction system was processed as follows: preheating at $98{ }^{\circ} \mathrm{C}$ for $5 \mathrm{~min} ; 30$ cycles of $30 \mathrm{~min}$ at $98^{\circ} \mathrm{C}, 30 \mathrm{~s}$ at $52^{\circ} \mathrm{C}, 1 \mathrm{~min}$ at $72{ }^{\circ} \mathrm{C}$ and extension at $72^{\circ} \mathrm{C}$ for $10 \mathrm{~min}$. The PCR products were detected using $1.5 \%$ gel electrophoresis.

Restriction sites were analysed using SnapGene (GSL Biotech, Chicago, IL, USA). The enzyme NheI cleavage system was performed in a $20 \mu \mathrm{l}$ volume containing $5 \mu \mathrm{l}$ of PCR product, $2 \mu \mathrm{l}$ of $10 \times$ FastDigest Green Buffer, $1 \mu \mathrm{l}$ of FastDigest enzyme and $12 \mu \mathrm{l}$ of Milli-Q water. The system was also suitable for the other two enzymes including HincII and $P v u I I$. All reaction systems were incubated at $37^{\circ} \mathrm{C}$ for $10 \mathrm{~min}$ in a digital dry bath and then inactivated by heating to $65^{\circ} \mathrm{C}$ for $5 \mathrm{~min}$. The products were assessed on $1.5 \%$ agarose gels in Tris-acetate buffer and photographed after staining with a nucleic acid dye, GelStain (TransGen Biotech, Beijing, China P.R.). The strains were classified based on the results of three cleavage reactions.

\section{High-performance liquid chromatography for aflatoxins}

In total, 156 A. flavus isolates and two A. parasiticus strains were selected for the evaluation of aflatoxin production ability when cultured using natural soybean substrates. $\mathrm{AFB}_{1}, \mathrm{AFB}_{2}, \mathrm{AFG}_{1}$ and $\mathrm{AFG}_{2}$ aflatoxin production abilities were determined using HPLC according to Shotwell et al. (1966) with slight modification. Each strain was inoculated on $75 \mathrm{~g}$ autoclaved soybean and $25 \mathrm{ml}$ sterile water in a $250 \mathrm{ml}$ Erlenmeyer flask with a $1.5 \mathrm{ml}$ conidial suspension rate that was obtained from the DG18 medium after 7-day culture. The cultures were incubated at $30^{\circ} \mathrm{C}$ in the dark for 27 days.

At the end of the incubation, the soybean was autoclaved at $121{ }^{\circ} \mathrm{C}$ for $30 \mathrm{~min}$ to inactivate the strains. The cultures were ground using a high-speed crusher, and then $5 \mathrm{~g}$ of the mixture was added into a $125 \mathrm{ml}$ Erlenmeyer flask with $1 \mathrm{~g} \mathrm{NaCl}$. Afterwards, $100 \mathrm{ml}$ of methanol-water $(70: 30, v / v)$ was added to extract the aflatoxins. After 
high-speed homogenisation, the liquid-phase extract was filtered through a layer of rapid qualitative philtre paper. Subsequently, $10 \mathrm{ml}$ of the filtrate was mixed with $20 \mathrm{ml}$ of water and the mixture was filtered using microfiber philtre paper, and then $15 \mathrm{ml}$ of the filtrate was added into an aflatoxin $B_{1} / B_{2} / G_{1} / G_{2}$ immunoaffinity column (Beijing Huaan Maike Biotechnology Co., Ltd., Being, China P.R.).

When the toxin content in the sample was higher than the column capacity ( $300 \mathrm{ng})$, the sample volume was reduced appropriately, or the dilution factor was increased. Finally, the AFs were dissolved in $1 \mathrm{ml}$ methanol.

Afterwards, the mixture of the dissolved AFs was injected into an Alliance e2695 HPLC system (Waters, Milford, MA, USA) equipped with a 2475 fluorescence detector (excitation $365 \mathrm{~nm}$, emission $450 \mathrm{~nm}$ ) and an autosampler system. The loading volume was $10 \mu$ l. An improved photochemical reactor (AURA, New York, NY, USA, $230 \mathrm{Volt}, 50 \mathrm{~Hz}, 8 \mathrm{Watt}$ ) was installed between the analytical column (Waters, XBridge C18 $5 \mu \mathrm{m}, 4.6 \times 250 \mathrm{~mm}$ ) and the fluorescence detector. The isocratic mobile phase contained methanol: water $(1: 1, \mathrm{v} / \mathrm{v})$ and was eluted at a flow rate of $0.5 \mathrm{ml} / \mathrm{min}$.

Data were normalised according to the calibration curves of standard solutions of $\mathrm{AFB}_{1}$ and $\mathrm{AFG}_{1}$ (both 1000, 500, 300, 100, 10 and $2.0 \mathrm{ng} / \mathrm{ml}$ ) and $\mathrm{AFG}_{2}$ and $\mathrm{AFB}_{2}$ (both $300,150,90,30,3$ and $0.6 \mathrm{ng} / \mathrm{ml})$. The detection and quantification limits were 0.5 and $0.75 \mathrm{ng} / \mathrm{ml}$, for $\mathrm{AFB}_{1}$ and $\mathrm{AFG}_{1}$, respectively, and were 0.15 and $0.225 \mathrm{ng} / \mathrm{ml}$, respectively, for $\mathrm{AFB}_{2}$ and $\mathrm{AFG}_{2}$.

\section{The mycelium growth rate and confrontation assay}

The non-aflatoxigenic $A$. flavus isolated in the study and aflatoxigenic $A$. flavus that produced the highest $\mathrm{AFB}_{1}$ amounts were cultured on potato dextrose agar (PDA) plates and incubated at $25^{\circ} \mathrm{C}$ for 9 days. Colony diameters of each plate were observed. Three replicates were included for each strain.

The non-aflatoxigenic $A$. flavus strains that grew most rapidly based on colony diameter after incubation for $72 \mathrm{~h}$ were cultured on PDA agar and natural soybean substrates together with the aflatoxigenic $A$. flavus that produced the highest $\mathrm{AFB}_{1}$ quantities. Non-toxigenic $A$. flavus and toxigenic $A$. flavus were inoculated at the same time on the PDA plate (culture dish diameter: $8.5 \mathrm{~cm}$ ) $2 \mathrm{~cm}$ from the centre on both sides. The aflatoxigenic A. flavus was inoculated on the same location of the PDA plate as a control group. Plate confrontation assay was performed at $30{ }^{\circ} \mathrm{C}$ and repeated thrice. The diameters of the strain colonies were observed daily. When the hyphae of the control culture filled the whole petri dish, the diameters of the tested non-aflatoxigenic $A$. flavus pointing to the aflatoxigenic $A$. flavus, the diameters of the aflatoxigenic $A$. flavus pointing to the non-aflatoxigenic $A$. flavus and the diameters of the control aflatoxigenic A. flavus were measured respectively. The inhibition ratio was calculated according to Equation 1.

$$
\text { Inhibition ratio }(\%)=\frac{\begin{array}{l}
\text { diameter of toxigenic } \\
\text { A. flavus in control - } \\
\text { diameter of toxigenic } \\
\text { A. flavus in confrontation }
\end{array}}{\begin{array}{c}
\text { diameter of toxigenic } \\
\text { A. flavus in control }
\end{array}} \times 100 \text { (1) }
$$

The spore suspensions of toxigenic and non-toxigenic $A$. flavus were prepared using $10^{6} \mathrm{cfu} / \mathrm{ml}$ concentrations. Using soybean as the culture medium, $1.5 \mathrm{ml}$ aflatoxin producing and $1.5 \mathrm{ml}$ non-aflatoxin producing spores were added as the experimental groups. In the control group, only the aflatoxin producing $A$. flavus spore solution was added. Three parallel experiments were performed for each group. $\mathrm{AFB}_{1}$ presence in each group was evaluated after incubation at $30{ }^{\circ} \mathrm{C}$ for 27 days. The inhibition ratio was calculated according to Equation 2.

$$
\text { Inhibition ratio }(\%)=\frac{\begin{array}{c}
\mathrm{AFB}_{1} \text { production in } \\
\text { control }-\mathrm{AFB}_{1} \text { production } \\
\text { in confrontation }
\end{array}}{\begin{array}{c}
\mathrm{AFB}_{1} \text { production } \\
\text { in control }
\end{array}} \times 100(2)
$$

\section{Results}

\section{Phenotypic characterisation}

In total, 312 isolates of Aspergillus section Flavi were isolated from four major peanut-growing regions of China, and 156 strains were identified as A. flavus or A. parasiticus when the reverse side of the colony on AFPA was orange. In contrast, $A$. oryzae and $A$. sojae isolates exhibit yellow or brown colours on AFPA. Example plates of the four Aspergillus strains are presented in Supplementary Figure S1. The yyPAsp-nn designation code was employed, where yy, P, Asp and nn refer to the year, the commodity (peanut), the genus Aspergillus and the isolate special number, respectively.

\section{Sequence analysis}

Genetic identification of the isolates was achieved using genomic sequencing at two regions of the Aspergillus section Flavi genome. First, the results of all $28 S$ rRNA and calmodulin sequences analysed using DNAMAN (Lynnon Biosoft, Quebec, Canada) suggested that similarity was over $95 \%$. Secondly, based on the data in public databases searched using the BlastN algorithm, $28 S$ rRNA and 
calmodulin sequences showed more than $93 \%$ of identity with $A$. flavus.

\section{PCR-RFLP results}

PCR amplification and sequence analysis of Aspergillus strains demonstrated the amplified fragment was identical to the sequences of the designed $a f l R$ gene promoter (515 bp) and the aflR structural gene (798 bp) (Figure 1). The aflR promoter of the Aspergillus strains was tested using PCR and its sequences were analysed using DNAMAN. The sequences of the $a f l R$ promoter in $A$. parasiticus were similar, but had one more base when compared to A.flavus, $A$. sojae and $A$. oryzae. In addition, the promoter sequences among the non-toxigenic $A$. flavus, $A$. oryzae and $A$. sojae were identical. NheI enzyme digestion analysis revealed that toxigenic $A$. flavus and $A$. parasiticus both had one restriction enzyme cutting site, while non-aflatoxigenic $A$. flavus, $A$. oryzae and $A$. sojae all had no NheI site (Supplementary Table S2). Analysis of aflR structural gene PCR amplification sequences revealed that $A$. flavus had two HincII enzyme cutting sites and A. parasiticus had one cleavage site, while PvuII of aflR structural gene showed that $A$. flavus had one restriction enzyme site and $A$. parasiticus had two restriction sites (Supplementary Table S3).

The aflR promoter fragment was digested with restriction endonuclease NheI; the aflR structural gene fragment was digested with restriction enzymes HincII and PvuII separately. The electrophoretic detection results are illustrated in Figure 1. The enzyme digestion results were consistent with the bioinformatics analysis of GenBank resources and other studies (Somashekar et al., 2004; Shao et al., 2008).

\section{Production of mycotoxins}

Under the selected chromatographic conditions, the AFs were well separated. Supplementary Figure S2 shows the chromatograms of aflatoxin standards with $1000 \mathrm{ng} / \mathrm{ml}$ $\mathrm{AFG}_{1}$ and $\mathrm{AFB}_{1}$ and $300 \mathrm{ng} / \mathrm{ml} \mathrm{AFG}_{2}$ and $\mathrm{AFB}_{2}$. Mycotoxins were produced by $86.5 \%(135 / 156)$ of the Aspergillus section Flavi isolates studied. Table 2 presents different aflatoxin quantification and aspergillic acid and sclerotium production trends of the Aspergillus section Flavi strains. Among the A. flavus screened (156), 135 (86.5\%) of the strains produced $\mathrm{AFB}_{1}$ and $\mathrm{AFB}_{2}$ at 7.77 to $5,712.81$ and 0.89 to $589.88 \mu \mathrm{g} / \mathrm{kg}$, respectively. The production of $\mathrm{AFB}_{1}$ was much higher than the production $\mathrm{AFB}_{2}$. The average mycotoxin production levels are listed in Table 2. The two $A$. parasiticus strains both produced all the aflatoxins $\left(\mathrm{AFG}_{2}\right.$, $\mathrm{AFG}_{1}, \mathrm{AFB}_{2}$ and $\mathrm{AFB}_{1}$ ), whereas $A$. parasiticus 3.0124 produced more aflatoxins than $A$. parasiticus JS (Table 2 ).

\section{Sclerotium production}

The presence, shape and size of sclerotia were observed after the strains were cultured in the $\mathrm{CZ}$ medium at $30{ }^{\circ} \mathrm{C}$ for 14 days. Sclerotia were produced by 125 of $156 \mathrm{~A}$. flavus isolates, but by neither of the two $A$. parasiticus strains (Table 2$)$. All the sclerotia were L-type $(>400 \mu \mathrm{m})$, which were round to elongate. The average size of the sclerotia was $570 \pm 90 \mu \mathrm{m}$ for A. flavus strains. About

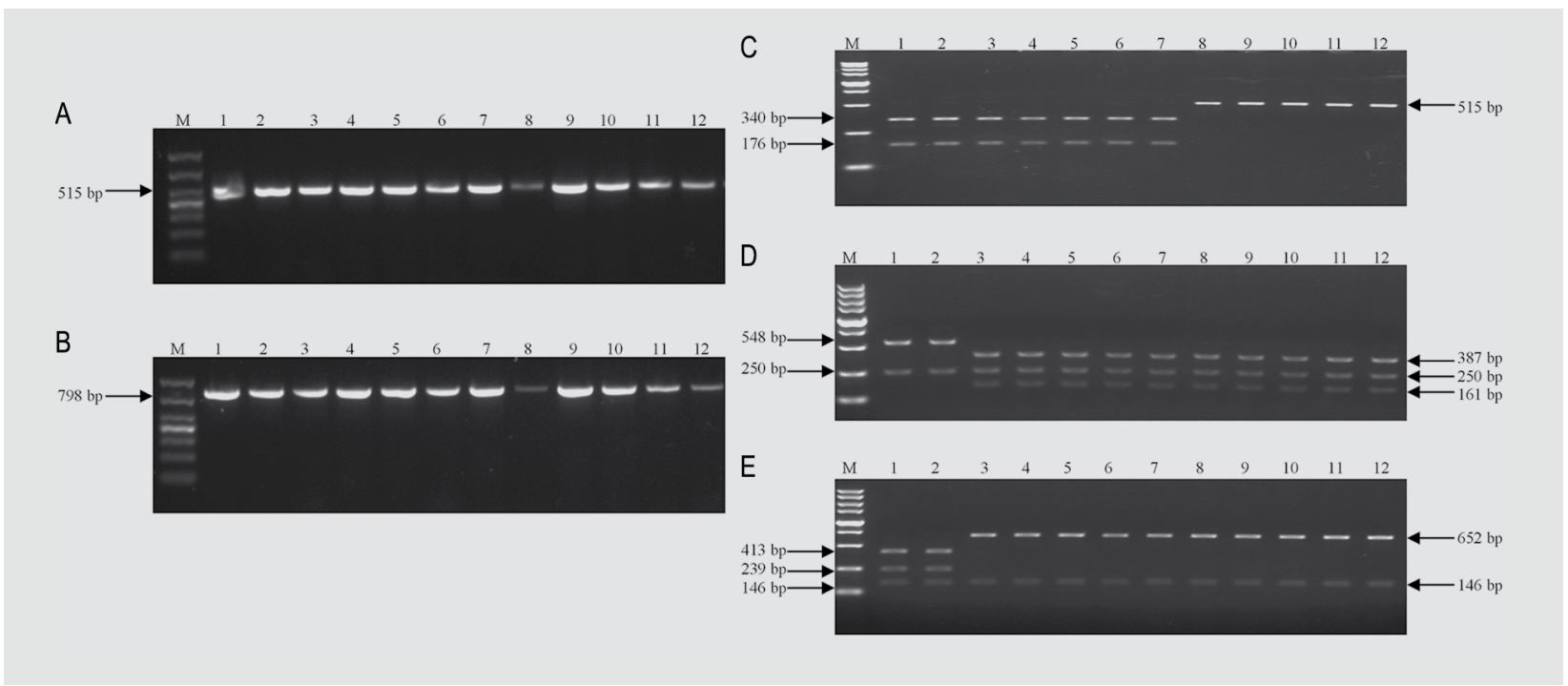

Figure 1. Agarose gel electrophoresis of the target gene products and enzyme digestion results. (A) PCR amplification of the afIR promoter; (B) amplification of the afIR structural gene; (C) afIR promoters digested using Nhel; (D) afIR digested using Hincll; (E) afIR digested using Pvull. $M=$ Marker DL1000; 1 = Aspergillus parasiticus 3.124; 2 = A. parasiticus JS; 3 = strain 18PAsp-xy1; 4 = strain 18PAsp-xy2; 5 = strain 18PAsp-ts2; 6 = strain 18PAsp-wy4; $7=$ Aspergillus flavus $3.4408 ; 8=$ non-aflatoxigenic $A$. flavus $\mathrm{H} 1 ; 9$ = non-aflatoxigenic $A$. flavus $\mathrm{H} 2 ; 10$ = strain 18PAsp-zy1; 11 = Aspergillus oryzae 3.484; 12 = Aspergillus sojae 3.880 . 
Table 2. Different aflatoxin quantification, aspergillic acid and sclerotium production trends of Aspergillus strains.

\begin{tabular}{|c|c|c|c|c|c|c|c|c|}
\hline \multirow[t]{2}{*}{ Species } & \multirow{2}{*}{$\begin{array}{l}\text { Number of } \\
\text { isolates (\%) }\end{array}$} & \multicolumn{5}{|c|}{ Average mycotoxin production ${ }^{1}(\mu \mathrm{g} / \mathrm{kg})$} & \multirow[t]{2}{*}{$\mathrm{AA}^{2}$} & \multirow{2}{*}{$\begin{array}{l}\text { Number of sclerotium } \\
\text { producers }(\%)\end{array}$} \\
\hline & & $\mathrm{AFB}_{1}$ & $\mathrm{AFB}_{2}$ & $\mathrm{AFG}_{1}$ & $\mathrm{AFG}_{2}$ & Total & & \\
\hline A. flavus & $135(86.5 \%)$ & 936.72 & 87.69 & ND & ND & $1,024.41$ & + & $108(86.4)$ \\
\hline A. flavus & $21(13.5 \%)$ & ND & ND & ND & ND & ND & + & $17(13.6 \%)$ \\
\hline A. parasiticus 3.0124 & -3 & 430.02 & 108.47 & $1,630.88$ & 214.27 & $2,383.64$ & + & 0 \\
\hline A. parasiticus JS & -3 & 130.13 & 46.54 & 321.72 & 74.38 & 572.77 & + & 0 \\
\hline
\end{tabular}

108 of 135 aflatoxigenic $A$. flavus isolates and 17 of 21 non-aflatoxigenic isolates were sclerotium producers. In addition, $A$. flavus isolates producing sclerotia produced higher levels of aflatoxins (Supplementary Table S4).

\section{Mycelium growth rate and confrontation assay}

Water activity $\left(\mathrm{a}_{\mathrm{w}}\right)$ of the PDA agar detected by a moisture activity tester (GYW-1GS; Guana, Shenzhen, China P.R.) was 0.952 . The colony diameters increased linearly until the colonies reached the edge of the petri dishes. When the diameter was greater than or equal to $8.3 \mathrm{~cm}$, the plates were considered covered with hyphae. Four strains of $A$. flavus filled the petri dishes on the sixth day. Furthermore, mycelia of almost all strains reached their maximum size on the eighth day. After cultivation for $72 \mathrm{~h}$, the diameters of the non-toxigenic strains varied from 3.7 to $4.6 \mathrm{~cm}$. Fungal strain 18PAsp-zy1 was the fastest growing one. Figure 2 shows the growth curves of 18PAsp-zy1, 18PAspxy1 growing alone and 18PAsp-xy1 co-inoculated with non-toxigenic $A$. flavus. When the colony diameter of 18PAsp-xy1 cultured alone in PDA agar was $8.3 \mathrm{~cm}$, the diameter in the tested group was $3.7 \mathrm{~cm}$. The distance between toxigenic and non-toxigenic strains of $A$. flavus was about $0.5 \mathrm{~cm}$ (Figure 3). The inhibition of the nontoxigenic $A$. flavus on toxigenic $A$. flavus was $55.4 \%$. In the soybean culture, aflatoxin accumulation was reduced by more than $72 \%$ from $5,510.37 \mu \mathrm{g} / \mathrm{kg}$ to $1,509.84 \mu \mathrm{g} / \mathrm{kg}$.

\section{Discussion}

It is challenging to distinguish $A$. flavus and $A$. parasiticus from $A$. oryzae and $A$. sojae in numerous media due to their similar phenotypic characteristics. Their spores are similarly yellow coloured in DG18 medium and yellowgreen on CZ medium. We used the DG18 medium to select single isolates that resembled $A$. flavus. DG18 agar can retard or inhibit the growth of Brettanomyces anomalus,
Cryptococcus albidus and Rhodotorula mucilaginosa, which facilitates the selection of Aspergillus strains (Deak et al., 2001). Subsequently, based on the unique orange colour on AFPA medium, we can easily distinguish A. flavus and A. parasiticus from other Aspergillus Flavi isolates.

A. flavus, A. oryzae, A parasiticus and A. sojae belong to Aspergillus section Flavi. They all contain the aflR gene, and the aflR sequences are almost similar. We analysed the aflR promoter sequences and structural genes of $A$. flavus, A. parasiticus, $A$. oryzae and $A$. sojae and observed that some of the bases changed regularly, resulting in changes of restriction sites, such as NheI, PvuII and HincII. The aflR promoter sequence of the aflatoxin producing strains harboured an NheI cleavage site that divided the aflR promoter into two fragments of 176 and $340 \mathrm{bp}$ in length, while the cleavage site disappeared after the mutation, indicating that the toxin-producing isolates and the non-

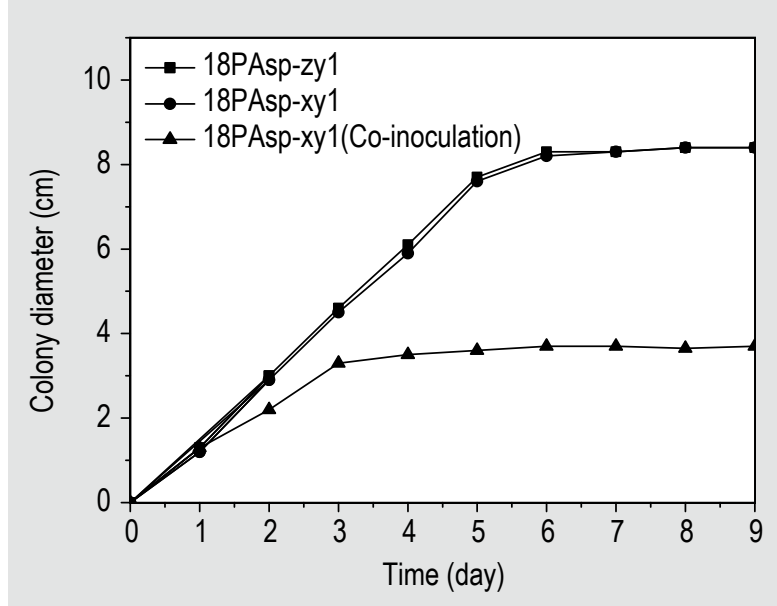

Figure 2. Growth curves of Aspergillus flavus strains 18PAspzy1 (non-toxigenic) and 18PAsp-xy1 (toxigenic) growing alone and co-inoculated. 


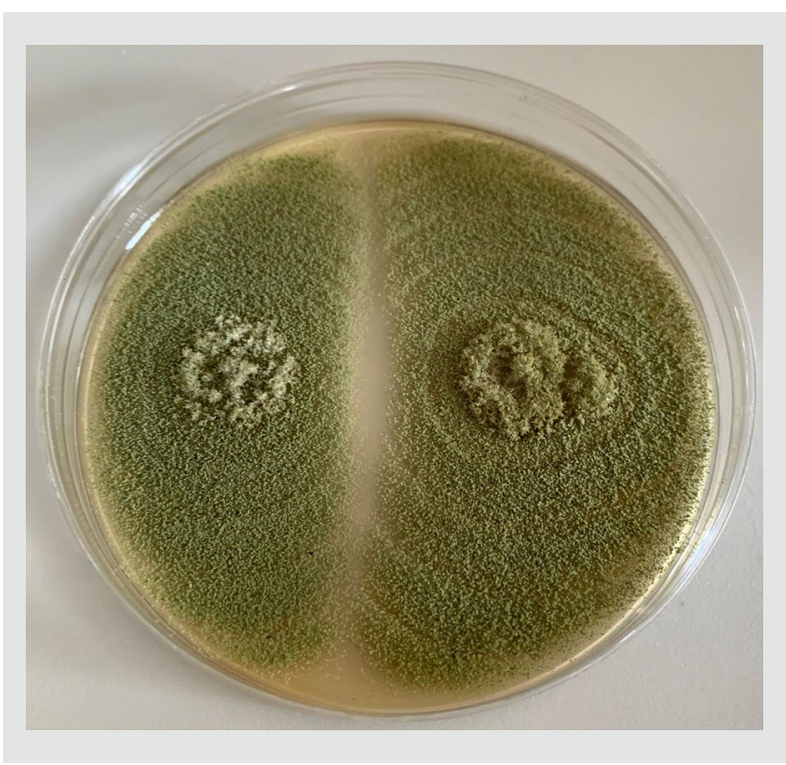

Figure 3. Toxigenic Aspergillus flavus strain 18PAsp-xy1 (left) co-inoculated with non-aflatoxigenic $A$. flavus strain 18PAspzy1 (right).

toxigenic isolates could be distinguished. The aflR gene was then digested with the PvuII enzyme and the HincII enzyme to distinguish $A$. flavus and $A$. parasiticus. Conventional PCR can separate Aspergillus using enzymatic digestion and agarose gel electrophoresis, and the results indicated that the gene sequences of toxigenic and non-toxigenic fungi were different. In addition, the aflatoxin producing abilities were verified using solid-state fermentation experiments.

The objective of the present study was to screen the nonaflatoxigenic strains of $A$. flavus from soil samples. Toxinproducing ability is often assessed through solid-state fermentation, which requires almost a month, in addition to being easily affected by the environment. Using the PCR-RFLP method, we can evaluate the capacities based on gene levels. The method requires only approximately a week to obtain the non-aflatoxigenic isolates. Therefore, it is possible to ensure that the screened non-aflatoxigenic strains have lost the toxin-producing ability.

The PCR-RFLP method established in the present study only focuses on the aflR gene. There are numerous atoxigenic strains with a functional $a f l R$ gene. The patterns of deletions in the aflatoxin biosynthetic gene cluster appear to be common and diverse. Chang et al. (2005) found eight deletion patterns among which three patterns contained aflR gene. In 2016, genotypes were divided into 6 groups (Group A to F) based on the presence or absence of genes in an $80 \mathrm{~kb}$ region consisting of aflatoxin biosynthesis and sugar clusters. In addition, small deletions $(<1 \mathrm{~kb})$ or SNPs in other aflatoxin biosynthesis genes also exist (Adhikari et $a l ., 2016)$. Therefore, relying on the presence or absence of a functional aflR gene would classify several atoxigenic strains as toxigenic inaccurately because their deletion or defect would be located in other aflatoxin biosynthesis genes.

The aflR genes could have already changed although they have been amplified, since the mutation of aflR only consists of several bases and does not particularly influence the amplification. In addition, there could be other relationships between $a f l R$ and other genes, which were not studied here. In our future studies, we could expand the screening range and verify the presence or absence of other regulatory genes involved in aflatoxin biosynthesis.

In the present study, strains identified as A. flavus and A. parasiticus were tested for their aflatoxin producing ability based on solid-state fermentation in soybean culture. Natural substrates, such as cereal grains have been demonstrated to be appropriate substrates for aflatoxin production in laboratory studies with better results (Gourama and Bullerman, 1995; Moreno Romo and Suárez Fernández, 1986). A. flavus only produce $\mathrm{AFB}_{1}$ and $\mathrm{AFB}_{2}$ and the production of $\mathrm{AFB}_{1}$ was much greater than that of $\mathrm{AFB}_{2}$. These results are consistent with those of other studies (Baquião et al., 2013; Magnoli et al., 1998). Ehrlich et al. (2004) revealed that that portions of the cypA gene were lost in A. flavus which was predicted to encode a cytochrome $\mathrm{P} 450$ monooxygenase needed in the process of oxidation from $\mathrm{B}$ aflatoxins to $\mathrm{G}$ aflatoxins. Thus $A$. flavus cannot produce $\mathrm{G}$ aflatoxins. The two $A$. parasiticus could produce $\mathrm{AFB}_{1}, \mathrm{AFB}_{2}, \mathrm{AFG}_{1}$ and $\mathrm{AFG}_{2}$. Notably, the two isolates produced more $\mathrm{AFG}_{1}$ than $\mathrm{AFB}_{1}$. The results are consistent with those of previous studies by Baquião et al. (2013) and Peromingo et al. (2016) who observed that AFG $_{1}$ amounts were always higher than $\mathrm{AFB}_{1}$ amounts under varying temperature and water conditions.

The aflatoxin biosynthesis gene cluster has been explored previously (Jiujiang et al., 2004). The structural genes are regulated by the transcription factor aflR and an accessory regulatory gene, aflS (Chang, 2003). Temperature and water are the key factors influencing $\mathrm{AFB}_{1}$ and $\mathrm{AFG}_{1}$ biosynthesis. According to the study, temperature changes were responsible for the differences between $\mathrm{AFB}_{1}$ and $\mathrm{AFG}_{1}$. Moreover, according to the study, $A$. parasiticus produced higher $\mathrm{AFG}_{1}$ concentrations at moderate temperatures (20$30{ }^{\circ} \mathrm{C}$ ), whereas $\mathrm{AFB}_{1}$ was produced at high temperatures $\left(>30^{\circ} \mathrm{C}\right)$ (Schmidt-Heydt et al., 2010).

Aspergillus strains can produce sclerotia on the CZ medium. In the present study, 125 (80.1\%) out of 156 A. flavus isolates produced sclerotia after incubation on $\mathrm{CZ}$ agar for 14 days, whereas none of the $A$. parasiticus, $A$. oryzae and $A$. sojae isolates produced any sclerotia. No absolute relationship was perceived between sclerotia and aflatoxin production capacity (Giorni et al., 2007). Aflatoxigenic and non-aflatoxigenic $A$. flavus strains similarly produced sclerotia at similar levels ( 80 vs $81 \%$ ); however, sclerotia- 
producing A. flavus strains seemed to be able to produce higher quantities of aflatoxins.

In this study, after the completion of screening, nonaflatoxigenic and aflatoxigenic $A$. flavus were cultured on plate confrontation and soybean culture medium. Indeed, the growth rate and toxin production of toxigenic A. flavus strains on confrontation cultures were inhibited. The mechanism of this inhibition has also been described in previous studies. Toxigenic and non-toxigenic $A$. flavus need the same nutrients for growth and reproduction, and there is competition between them. Therefore, a more rapid growth rate of fungal hyphae can ensure that nontoxigenic $A$. flavus strains rapidly occupy the ecological niche, compete for nutrition and grab the living space of toxigenic A. flavus to achieve the desired inhibition. Through repeated biological control applications, Weaver and Abbas (2019) tested the hypotheses that applied biocontrol strains competitively displace the indigenous toxigenic strains.

The adaptability of microbial agents to the environment, such as grain types, climate and water, is very important for the biological control effect. Therefore, non-toxigenic A. flavus strains screened locally often have more advantages (Moore et al., 2009; Mwakinyali et al., 2019). Non-aflatoxigenic $A$. flavus showed good inhibiting effects on toxigenic $A$. flavus in the mycelial growth and aflatoxin production experiment. Next, a field experiment should be conducted in order to test applicability of the atoxigenic strains.

\section{Conclusions}

A PCR-RFLP combined with morphological methods was developed for the screening of non-toxigenic $A$. flavus from soils. The aflatoxin producing capacities of the strains were verified using solid-state fermentation experiments. Although some non-toxigenic $A$. flavus strains could have been missed, it could be verified that the isolated nontoxigenic strains lost their capacity producing aflatoxins. Non-toxigenic $A$. flavus had a competitive inhibitory effect against the growth of toxigenic $A$. flavus in plate and natural soybean medium.

\section{Supplementary material}

Supplementary material can be found online at https://doi. org/10.3920/WMJ2019.2490.

Table S1. Information of experimental strains for PCRRFLP.

Table S2. Restriction analysis of the aflR promoters using NheI.
Table S3. Restriction analysis of the aflR gene using HincII and PvuII.

Table S4. Relation between average level of mycotoxin and sclerotium production.

Figure S1. Colony colour on the reverse of AFPA plates of different Aspergillus species.

Figure S2. The HPLC chromatogram of aflatoxin $\mathrm{G}_{2}, \mathrm{G}_{1}$, $\mathrm{B}_{2}$ and $\mathrm{B}_{1}$ standards.

\section{Acknowledgements}

The authors highly appreciate the financial supports from National Natural Science Foundation of China (U1604234), Special Fund for Grain-scientific Research in the Public Interest of China (201513006), National key research and development program (2017YFC1600604) and the basic scientific research funds programs in national non-profit scientific research institutes (ZX1911).

\section{Conflict of interest}

The authors declare no conflict of interest.

\section{References}

Adhikari, B.N., Bandyopadhyay, R. and Cotty, P.)., 2016. Degeneration of aflatoxin gene clusters in Aspergillus flavus from Africa and North America. AMB Express 6: 62.

Bandyopadhyay, R., Ortega-Beltran, A., Akande, A., Mutegi, C., Atehnkeng, J., Kaptoge, L., Senghor, A.L., Adhikari, B.N. and Cotty, P.J., 2016. Biological control of aflatoxins in Africa: current status and potential challenges in the face of climate change. World Mycotoxin Journal 9: 771-789.

Baquião, A.C., Oliveira, M.M.M.D., Reis, T.A., Zorzete, P., Atayde, D.D. and Correa, B., 2013. Polyphasic approach to the identification of Aspergillus section Flavi isolated from Brazil nuts. Food Chemistry 139: 1127-1132.

Barros, G.G.C., M. L, Reynoso, M.M., Torres, A.M. and Chulze, S.N., 2010. Molecular characterization of Aspergillus section Flavi isolates collected from peanut fields in Argentina using AFLPs. Journal of Applied Microbiology 103: 900-909.

Bhatnagar, D., Cary, J.W., Ehrlich, K., Yu, J. and Cleveland, T.E., 2006. Understanding the genetics of regulation of aflatoxin production and Aspergillus flavus development. Mycopathologia 162: 155-166.

Bhatnagar, D., Ehrlich, K.C. and Cleveland, T.E., 2003. Molecular genetic analysis and regulation of aflatoxin biosynthesis. Applied Microbiology and Biotechnology 61: 83-93.

Cardwell, K.F., Henry, S.H. and Abbas, H.K., 2008. Risk of exposure to and mitigation of effects of aflatoxin on human health: a West African example. Toxin Reviews 23: 213-235.

Chang, P.K., 2003. The Aspergillus parasiticus protein AFLJ interacts with the aflatoxin pathway-specific regulator AFLR. Molecular Genetics and Genomics 268: 711-719. 
Chang, P.K., Horn, B.W. and Dorner, J.W., 2005. Sequence breakpoints in the aflatoxin biosynthesis gene cluster and flanking regions in nonaflatoxigenic Aspergillus flavus isolates. Fungal Genetics and Biology 42: 914-923.

Chen, R. and Liu, Z.B., 2006. Promoter sequence mutations in the aflR gene of Aspergillus flavus are correlated with the production of aflatoxin. Chinese Journal of Cell Biology 28: 912-916.

Cotty, P.J., 1989. Virulence and cultural characteristics of two Aspergillus flavus strains pathogenic on cotton. Phytopathology 79: 808-814.

Cotty, P.J., 1990. Effect of atoxigenic strains of Aspergillus flavus on aflatoxin contamination of developing cottonseed. Plant Disease 74: 233-235.

Deak, T., Chen, J. and Golden, D.A., 2001. Comparison of dichloran 18\% glycerol (DG18) agar with general purpose mycological media for enumerating food spoilage yeasts. International Journal of Food Microbiology 67: 49-53.

Dorner, J.W. and Horn, B.W., 2007. Separate and combined applications of nontoxigenic Aspergillus flavus and A. parasiticus for biocontrol of aflatoxin in peanuts. Mycopathologia 163: 215-223.

Dorner, J.W. and Lamb, M.C., 2006. Development and commercial use of afla-Guard ${ }^{\oplus}$, an aflatoxin biocontrol agent. Mycotoxin Research 22: 33-38.

Dorner, J.W., Cole, R.J. and Blankenship, P.D., 1992. Use of a biocompetitive agent to control preharvest aflatoxin in drought stressed peanuts. Journal of Food Protection 55: 888-892.

Ehrlich, K.C., Montalbano, B.G., Bhatnagar, D. and Cleveland, T.E., 1998. Alteration of different domains in AFLR affects aflatoxin pathway metabolism in Aspergillus parasiticus transformants. Fungal Genetics and Biology 23: 279-287.

Ehrlich, K.C., Montalbano, B.G. and Cotty, P.J., 2003. Sequence comparison of aflR from different Aspergillus species provides evidence for variability in regulation of aflatoxin production. Fungal Genetics and Biology 38: 63-74.

Ehrlich, K.C., Perng-Kuang, C., Jiujiang, Y. and Cotty, P.J., 2004. Aflatoxin biosynthesis cluster gene cypA is required for $\mathrm{G}$ aflatoxin formation. Applied and Environmental Microbiology 70: 6518.

European Commission (EC), 2006. Commission Regulation (EC) No 1881/2006 of 19 December 2006 setting maximum levels for certain contaminants in foodstuffs. Official Journal of the European Union L 364: 5-24.

Galagan, J.E., Calvo, S.E., Cuomo, C., Ma, L.J., Wortman, J.R., Batzoglou, S., Lee, S.I., Baştürkmen, M., Spevak, C.C. and Clutterbuck, J., 2005. Sequencing of Aspergillus nidulans and comparative analysis with A. fumigatus and A. oryzae. Nature 438: 1105-1115.

Georgianna, D.R. and Payne, G.A., 2009. Genetic regulation of aflatoxin biosynthesis: from gene to genome. Fungal Genetics and Biology 46: 113-125.

Giorni, P., Magan, N., Pietri, A., Bertuzzi, T. and Battilani, P., 2007. Studies on Aspergillus section Flavi isolated from maize in northern Italy. International Journal of Food Microbiology 113: 330-338.

Gourama, H. and Bullerman, L.B., 1995. Aspergillus flavus and Aspergillus parasiticus: aflatoxigenic fungi of concern in foods and feeds: a review. Journal of Food Protection 58: 1395-1404.
Horn, B.W. and Dorner, J.W., 1998. Soil populations of Aspergillus species from section Flavi along a transect through peanut-growing regions of the United States. Mycologia 90: 767-776.

Horn, B.W. and Dorner, J.W., 1999. Regional differences in production of aflatoxin $\mathrm{B}_{1}$ and cyclopiazonic acid by soil isolates of Aspergillus flavus along a transect within the United States. Applied and Environmental Microbiology 65: 1444-1449.

International Agency for Research on Cancer (IARC), 1993. Some naturally occurring substances: food items and constituents, heterocyclic aromatic amines and mycotoxins. IARC Monographs on the evaluation of carcinogenic risks to humans. Vol. 56. IARC, Lyon, France.

Jiang, J., Yan, L. and Ma, Z., 2009. Molecular characterization of an atoxigenic Aspergillus flavus strain AF051. Applied Microbiology and Biotechnology 83: 501.

Jiujiang, Y., Perng-Kuang, C., Ehrlich, K.C., Cary, J.W., Deepak, B., Cleveland, T.E., Payne, G.A., Linz, J.E., Woloshuk, C.P. and Bennett, J.W., 2004. Clustered pathway genes in aflatoxin biosynthesis. Applied and Environmental Microbiology 70: 1253.

Keller, N.P. and Hohn, T.M., 1997. Metabolic pathway gene clusters in filamentous fungi. Fungal Genetics and Biology 21: 17-29.

Kowalska, A., Walkiewicz, K., Kozieł, P. and Muc-Wierzgoń, M., 2017. Aflatoxins: characteristics and impact on human health. Postepy Higieny i Medycyny Doswiadczalnej 71: 315.

Li, P., Zhang, Q. and Zhang, W., 2009. Immunoassays for aflatoxins. Trends in Analytical Chemistry 28: 1115-1126.

Liu, Y. and Wu, F., 2010. Global burden of aflatoxin-induced hepatocellular carcinoma: a risk assessment. Environmental Health Perspectives 118: 818-824.

Magnoli, C., Dalcero, A.M., Chiacchiera, S.M., Miazzo, R. and Saenz, M.A., 1998. Enumeration and identification of Aspergillus group and Penicillium species in poultry feeds from Argentina. Mycopathologia 142: 27-32.

Matsushima, K., Chang, P.K., Yu, J., Abe, K., Bhatnagar, D. and Cleveland, T.E., 2001. Pre-termination in aflR of Aspergillus sojae inhibits aflatoxin biosynthesis. Applied Microbiology and Biotechnology 55: 585.

Mauro, A., Garcia-Cela, E., Pietri, A., Cotty, P.J. and Battilani, P., 2018. Biological control products for aflatoxin prevention in Italy: commercial field evaluation of atoxigenic Aspergillus flavus active ingredients. Toxins 10: 30.

Moore, G.G., Singh, R., Horn, B.W. and Carbone, I., 2009. Recombination and lineage-specific gene loss in the aflatoxin gene cluster of Aspergillus flavus. Molecular Ecology 18: 4870-4887.

Moreno Romo, M.A. and Suárez Fernández, G., 1986. Aflatoxinproducing potential of Aspergillus flavus strains isolated from Spanish poultry feeds. Mycopathologia 95: 129-132.

Mwakinyali, S.E., Ding, X., Ming, Z., Tong, W., Zhang, Q. and Li, P., 2019. Recent development of aflatoxin contamination biocontrol in agricultural products. Biological Control 128: 31-39.

Nierman, W.C., Pain, A., Anderson, M.J., Wortman, J.R., Kim, H.S., Arroyo, J., Berriman, M., Abe, K., Archer, D.B. and Bermejo, C., 2005. Genomic sequence of the pathogenic and allergenic filamentous fungus Aspergillus fumigatus. Nature 438: 1151. 
O’Donnell, K., Nirenberg, H.I., Aoki, T. and Cigelnik, E., 2000. A multigene phylogeny of the Gibberella fujikuroi species complex: detection of additional phylogenetically distinct species. Mycoscience 41: 61-78.

Paula, R., Armando, V., Zofia, K. and Nelson, L., 2009. A polyphasic approach to the identification of aflatoxigenic and non-aflatoxigenic strains of Aspergillus section Flavi isolated from Portuguese almonds. International Journal of Food Microbiology 129: 187-193.

Peromingo, B., Rodríguez, A., Bernáldez, V., Delgado, J. and Rodríguez, M., 2016. Effect of temperature and water activity on growth and aflatoxin production by Aspergillus flavus and Aspergillus parasiticus on cured meat model systems. Meat Science 122: 76-83.

Pitt, J.I. and Hocking, A.D., 2006. Mycotoxins in Australia: biocontrol of aflatoxin in peanuts. Mycopathologia 162: 233-243.

Price, M.S., Yu, J., Nierman, W.C., Kim, H.S., Pritchard, B., Jacobus, C.A., Bhatnagar, D., Cleveland, T.E. and Payne, G.A., 2010. The aflatoxin pathway regulator $A f l R$ induces gene transcription inside and outside of the aflatoxin biosynthetic cluster. FEMS Microbiology Letters 255: 275-279.

Rokas, A., Payne, G., Fedorova, N.D., Baker, S.E., Machida, M., Yu, J., Georgianna, D.R., Dean, R.A., Bhatnagar, D. and Cleveland, T.E., 2007. What can comparative genomics tell us about species concepts in the genus Aspergillus? Studies in Mycology 59: 11-17.
Schmidt-Heydt, M., Rüfer, C.E., Abdel-Hadi, A., Magan, N. and Geisen, R., 2010. The production of aflatoxin $B_{1}$ or $G_{1}$ by Aspergillus parasiticus at various combinations of temperature and water activity is related to the ratio of aflS to aflR expression. Mycotoxin Research 26: 241-246.

Varga, J., Frisvad, J. and Samson, R., 2009. A reappraisal of fungi producing aflatoxins. World Mycotoxin Journal 2: 263-277.

Weaver, M.A. and Abbas, H.K., 2019. Field displacement of aflatoxigenic Aspergillus flavus strains through repeated biological control applications. Frontiers in Microbiology 10: 1788.

Yin, Y., Yan, L., Jiang, J. and Ma, Z., 2008. Biological control of aflatoxin contamination of crops. Journal of Zhejiang University-Science B (Biomedicine \& Biotechnology) 23: 787-792.

Yu, J., Chang, P.K., Bhatnagar, D. and Cleveland, T.E., 2000. Genes encoding cytochrome $\mathrm{P} 450$ and monooxygenase enzymes define one end of the aflatoxin pathway gene cluster in Aspergillus parasiticus. Applied Microbiology and Biotechnology 53: 583.

Yu, J., Chang, P.K., Bhatnagar, D. and Cleveland, T.E., 2002. Cloning and functional expression of an esterase gene in Aspergillus parasiticus. Mycopathologia 156: 227.

Zanon, M.S.A., Chiotta, M.L., Giaj-Merlera, G., Barros, G. and Chulze, S., 2013. Evaluation of potential biocontrol agent for aflatoxin in Argentinean peanuts. International Journal of Food Microbiology 162: 220-225. 